\title{
Analise Ergonômiça do Posto de Trabalho de uma Oficina de Órteses e Próteses para Reabilitação de Pessoas com Deficiência
}

\section{Ergonomic Analysis of a Workstation in a Workshop for Forming of Orthotics and Prosthetics}

Giorgio Gilwan da Silva', Tiago R. Mattozo ${ }^{2}$

Eugenio Andrés Diaz Merino ${ }^{3}$, Vilson J. Batista ${ }^{4}$ 


\section{Resumo}

A presente pesquisa foi elaborada com o objetivo de averiguar as condições ergonômicas de um posto de trabalho em uma oficina de conformação de órteses e próteses. Essa pesquisa se caracteriza por uma pesquisa descritiva de abordagem qualitativa. Apresenta como procedimentos técnicos a pesquisa bibliográfica e o estudo de caso, apoiados por visitas técnicas e entrevistas semiestruturadas. A análise do posto de trabalho foi desenvolvida a partir da utilização da Análise Ergonômica do Trabalho (AET) na empresa Ortonew, especializada na comercialização e confecção de órteses e próteses. Os resultados diagnosticaram pontos positivos e negativos do posto de trabalho observado. Pontos positivos: alternância entre trabalho sentado e trabalho em pé, permissão de pausas/intervalos, horário de trabalho relativamente flexível, música ambiente e clima organizacional amistoso. Os principais pontos negativos identificados são relacionados ao mobiliário (bancada e cadeira), às posturas, à ausência de uso de equipamentos de proteção individual (EPIs) e uso de instrumentos perigosos.

Palavras-Chave: Ergonomia, trabalho, Diagnóstico, Tecnologia.

\section{Abstract}

The present research was developed with the objective of investigating the ergonomic conditions of a workstation in a workshop of conformation of orthoses and prostheses. This research is characterized by a descriptive research of qualitative approach. The technical procedures used were the bibliographic research and the case study, supported by technical visits and semi-structured interviews. The analysis of the workstation was developed from the use of Ergonomic Analysis of Work in Ortonew company, specializing in the sale and manufacture of orthoses and prostheses. The results diagnosed positive and negative points of the work observed. Positive Points: alternating between work sitting and standing, permission of pauses/breaks, working hours relatively flexible, music environment and organizational climate friendly. The main weaknesses identified are related to furniture (chair and bench), the postures, the lack of use of personal protective equipment (PPE) and use of dangerous instruments.

Keywords: Ergonomics, work, Diagnosis e Technology.

ISSN: 1808-3129

\footnotetext{
${ }^{1}$ Designer Gráfico formado na UDESC, Especialização em Design Gráfico e Estratégia Coorporativa e Mestrado na Engenharia e Gestão do Conhecimento. UFSC. UNIVALI - Universidade do Vale do Itajaí, Brasil, giorgiogilwan@gmail.com

${ }^{2}$ Mestrando do Pós-Design/UFSC. Bacharel em Design Industrial - UDESC tiagomattozo@gmail.com
}

${ }^{3}$ Orientador, Prof. Dr. da Universidade Federal de Santa Catarina - UFSC, Florianópolis - SC - Brasil eugenio.merino@ufsc.br

4 Orientador, Prof. Dr. da Universidade Federal de Santa Catarina - UFSC,

Florianópolis - SC - Brasil - vbatista19 at gmail.com 


\section{INTRODUÇÃO}

Dados do censo IBGE (2010) indicam que 45,6 milhões de pessoas declaram possuir algum tipo de deficiência. Com base nestes dados, o Governo Federal lançou, por meio do Decreto 7.612, de 17 de novembro de 2011, o Plano Nacional dos Direitos da Pessoa com Deficiência (PNDP) - Viver sem Limite, para que todas as pessoas com deficiência alcancem equiparação de oportunidades e não sejam impossibilitadas de realizar sonhos, desejos e projetos de vidas. Independentemente do tipo ou grau de deficiência, todas as pessoas com deficiência necessitam de algum recurso tecnológico que the auxilie na execução de suas tarefas ou locomoção da melhor forma possível.

Sendo inúmeras as deficiências registradas pelo censo de 2010, igualmente inúmeros são os tipos de aparelhos ortopédicos necessários para supri-las. Esta demanda variada e crescente é atendida por oficinas especializadas, que devem seguir leis e normas regulamentadoras das atividades, com o intuito de uniformizar os procedimentos para a execução de produtos ortopédicos.

O processo de confecção de órteses e próteses sob medida é extremamente complexo e deve ser sempre prescrito por um médico ou fisioterapeuta. A simples distorção no tipo de produto é capaz de acarretar maléficas consequências aos usuários do produto. Por isso, é importante que as oficinas forneçam produtos assistivos dentro dos conceitos modernos de ergonomia.

Além de aplicar conceitos de ergonomia nos produtos que fabricam, as oficinas devem observá-los também no posto de trabalho da confecção de órteses e próteses. Melhor dizendo: a ergonomia é fundamental na concepção de produtos e também nos projetos de postos de trabalho, não apenas para resguardar a saúde do trabalhador, mas também para que a qualidade dos processos, dos produtos e a produtividade sejam preservadas.

Durante uma jornada de trabalho, os trabalhadores podem costumam adotar posturas diferentes e demandar esforços musculares e outras situações de risco que, no futuro, são aptas a causar doenças ocupacionais. As dores e o desconformo causados pela falta de ergonomia em postos de trabalho acarretam não apenas o afastamento dos trabalhadores do serviço, mas especialmente o mau desempenho das suas tarefas, quando presentes em seus postos. Postos de trabalho bem projetados tornam-se seguros para a saúde dos trabalhadores e produtivos para a empresa; postos de trabalho mal projetados acarretam afastamento de empregados e piora no seu desempenho.

O cerne desta pesquisa gira em torno destas questões, partindo-se da premissa de que é necessário que o posto de trabalho da oficina que desenvolve produtos para deficientes assegure condições favoráveis ao desempenho das atividades pelos seus colaboradores, pois é notório que o conforto, a satisfação, e o interesse do trabalhador, têm como consequência maior precisão na realização das tarefas, o que é imprescindível no processo de confecção de órteses e próteses, já que, como se disse, qualquer distorção no produto pode comprometer sua qualidade e o resultado esperado. 
Diante do exposto, esta pesquisa tem como objetivo averiguar as condições de um posto de trabalho em uma oficina de confecção de órteses e próteses. Foi selecionada para a pesquisa de campo a empresa Ortonew - Técnica Ortopédica, localizada em Florianópolis/SC, e no ambiente empresarial um posto de trabalho de confecção de órteses e próteses.

Justifica-se a relevância da pesquisa, porque seu foco principal é a qualidade de vida do ser humano e as condições ideais de trabalho, com reflexos diretos na qualidade dos produtos e na produtividade da empresa.

\subsection{Procedimentos Metodológicos}

Optou-se pela pesquisa qualitativa e exploratória, nos procedimentos de estudo de caso, por meio de entrevistas, observações in loco da execução das tarefas, registro fotográfico, onde se buscou analisar a efetiva condição de um posto de trabalho. O estudo foi desenvolvido a partir da utilização da Análise Ergonômica do Trabalho $(\mathrm{AET})$, análise da demanda, análise da tarefa e análise da atividade. A análise ergonômica de uma situação de trabalho é realizada pelo entendimento da situação geral (demanda), do trabalho prescrito e condições físicas e organizacionais (tarefa) e de como o trabalho é realmente realizado individualmente por cada usuário/operador (atividade) (DUL, 2004).

O posto de trabalho analisado foi o de processos de acabamento de órteses, definido a partir de relatórios de problemas de saúde no trabalho com dados sobre o afastamento do profissional deste posto. A análise do trabalho foi realizada com um trabalhador deste posto. Para efetivação do processo de análise ergonômica descreveu-se o ambiente trabalho onde se encontra o posto de trabalho; as tarefas envolvidas no processo de acabamento das órteses (trabalho prescrito). A Análise da Tarefa foi realizada com base em entrevistas e observações com visitas ao local, para identificar o trabalho prescrito e o realizado de fato no posto de trabalho, bem como verificar os fatores de risco ocupacionais. A pesquisa foi realizada nos meses de março e abril de 2014.

\subsubsection{Técnicas Utilizadas Na Análise Do Trabalho}

Dul (2004) divide as técnicas utilizadas em Ergonomia em técnicas objetivas e subjetivas:

Técnicas objetivas ou diretas: - Técnicas que tratam do registro das atividades ao longo de um período, por exemplo, através de um registro em vídeo e fotografias.

Técnicas subjetivas ou indiretas:- Técnicas que tratam do discurso do operador são os questionários e as entrevistas. Esta etapa forneceu uma gama de dados que favoreceram a análise do trabalho.

Os resultados obtidos em cada etapa serviram de base para a formulação do diagnóstico verificado na empresa e a partir deste, em outro momento da pesquisa propor ações para melhoria do posto em análise. As bases teóricas que são abordadas na sequência fundamentam a análise ergonômica de trabalho, emanam da ergonomia do trabalho e da biomecânica ocupacional. 


\section{FUNDAMENTAÇÃO TEÓRICA \\ 2.1 Ergonomia}

A ergonomia estuda a interação entre homem e o seu ambiente de trabalho, através das interfaces do sistema homem-máquina-ambiente com intuito de melhorar a qualidade da relação deste sistema, facilitando a execução do trabalho.

A ergonomia tem como objetivos principais a saúde, segurança e satisfação do trabalhador. A eficiência vem como consequência destes objetivos, pois o estado laboral existe em plataformas e os estudos ergonômicos, podem sanar com varias situações de sofrimento e sacrifício (IIDA, 2005).

As diversas associações nacionais e internacionais existentes possuem suas próprias definições sobre ergonomia.

No Brasil, a ABERGO- Associação Brasileira de Ergonomia utiliza a seguinte definição. "A Ergonomia é o estudo das interações das pessoas com a tecnologia, a organização e o ambiente, objetivando intervenções e projetos que visem melhorar".

A IEA (International Ergonomics Association) define Ergonomia como:

Ergonomia (ou fatores humanos) é uma disciplina científica que estuda as interações dos homens com outros elementos do sistema, fazendo aplicações da teoria, princípios e métodos de projeto, com o objetivo de melhorar o bem-estar humano e o desempenho global do sistema (DUL; WEERDMEESTER, 2004).

Vidal (2000), por sua vez, define ergonomia como sendo:

[...] o conjunto de conhecimentos científicos relacionados ao homem, necessários na concepção de instrumentos, máquinas e dispositivos que possam ser utilizados com o máximo de conforto, segurança e eficiência no trabalho (VIDAL, 2000).

O autor também define ergonomia como: "uma atitude profissional que modifica o sistema de trabalho com propósito de adequar as atividades com eficiência, segurança e conforto" (VIDAL, 2000).

De acordo com os autores acima mencionados, a ergonomia estuda vários aspectos: a postura e os movimentos corporais (sentados, em pé, empurrando, puxando e levantando cargas); fatores ambientais (ruídos, vibrações, iluminação, clima, agentes químicos); informação (informações captadas pela visão, audição e outros sentidos); relações entre mostradores e controles, bem como cargos e tarefas (tarefas adequadas, interessantes). A conjugação adequada desses fatores permite projetar ambientes seguros, saudáveis, confortáveis e eficientes, tanto no trabalho quanto nos demais aspectos da vida cotidiana.

Ainda vale salientar que "os objetivos da ergonomia são influenciados por estudos antropométricos e biomecânicos relacionados ao bem estar das pessoas" (SHUVAL E DONCHIN, 2005). Considera-se importante para este estudo compreender as características do posto de trabalho, o que se abordará na sequência. 


\subsection{Espaço Físico e Posto de Trabalho}

Salvendy (2006) considera local de trabalho os assentos, as mesas, os equipamentos, a superfície de trabalho, as ferramentas, os controles e displays, assim como o espaço de deslocamento, as janelas e o conforto térmico. Ainda, destaca que em geral os postos de trabalho necessitam de melhora a fim de diminuir o desgaste físico dos trabalhadores; facilitar a execução das tarefas; garantir boas condições de saúde e segurança no trabalho; e assegurar o fácil alcance aos equipamentos.

O planejamento do layout do posto de trabalho é essencial para o aperfeiçoamento das condições de trabalho, com a consequente melhora do bem estar rendimento das pessoas, da eficiência dos fluxos de trabalho e uma melhoria na própria aparência do local.

lida (2005) complementa dizendo que o trabalho abrange não apenas aqueles executados com máquinas e equipamentos, mas também toda a situação em que ocorre o relacionamento entre o homem e uma atividade produtiva. $O$ autor segue explicando que o posto de trabalho pode ser definido como a menor unidade produtiva, geralmente envolvendo um homem e o seu local de trabalho, e aponta critérios para avaliar a adequação de um posto de trabalho, dentre os quais estão o tempo gasto na operação; o índice de erros e acidentes; a postura e os esforços físicos exigidos dos trabalhadores, onde é possivel determinar os principais pontos de concentração de tensões, que tendem a provocar dores e desconforto. Diante deste contexto, os critérios ergonômicos devidamente aplicados podem facilitar o trabalho executado pelo homem e os avanços tecnológicos auxiliam estes processos.

\subsection{Tecnologia Assistiva - Órteses e Próteses}

É pacífico que a evolução tecnológica costuma facilitar a vida humana, favorecendo e simplificando as atividades do cotidiano das pessoas.

O termo Tecnologia Assistiva, segundo Bersch (2008), é um utilizado para identificar os recursos e serviços que contribuem para proporcionar ou ampliar habilidades funcionais de pessoas com deficiência, promovendo uma vida mais independente e a inclusão social.

[...] são produtos, instrumentos, equipamentos ou tecnologia adaptados ou especialmente projetados para melhorar a funcionalidade de pessoas portadoras de deficiência, com mobilidade reduzida favorecendo autonomia pessoal (BRASIL, 2011).

Órteses são parelhos ortopédicos confeccionados a partir de tomada de medidas e moldagem em gesso até as etapas de confecção definitiva. Destina-se a suprir ou corrigir a alteração morfológica de um órgão, de um membro ou de um segmento de um membro, ou a deficiência de uma função (FIGURA 1). 


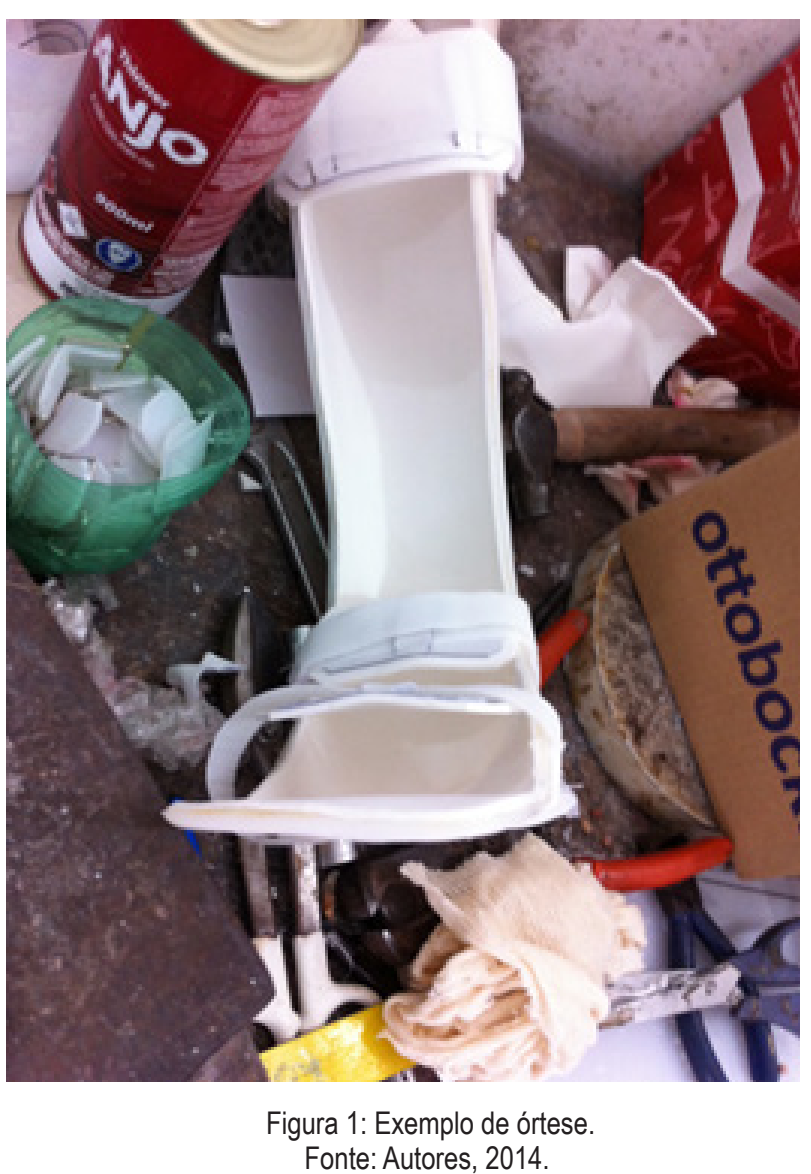

Estes aparelhos ortopédicos são produzidos de acordo com padrões e exigências legais em oficinas ortopédicas com Registro no Serviço de Vigilância Sanitária do Município e do Estado em que estejam sediadas, como é caso da empresa Ortonew, objeto desta pesquisa.

\subsection{Análise Ergonômica - AET}

\section{Wisner (2003) assim descreve Análise Ergonômica do Trabalho - AET: \\ [...] é uma intervenção, no ambiente de trabalho, para estudo dos desdobramentos e consequências físicas e psicofisiológicas, decorrentes da atividade humana no meio produtivo. Consiste em compreender a situação de trabalho, confrontar com aptidões e limitações à luz da ergonomia, diagnosticar situações críticas à luz da legislação oficial, estabelecer sugestões, alterações e recomendações de ajustes de processo, ajustes de produto, postos de trabalho, ambiente de trabalho. A AET busca estabelecer uma aproximação no que se refere à compreensão geral de pro- blemas relacionados com a organização do trabalho e seus reflexos em prováveis ocorrências de lesões físicas e transtornos psicofisiológicos (WISNER, 2003).}

A Análise Ergonômica AET é composta de quatro fases (VIDAL, 2003; WISNER, 1994):

Análise global: etapa inicial referente ao levantamento de dados globais da empresa em termos de razão social, estrutura, organograma, serviços, mercado, clientela, população trabalhadora, departamentos, hierarquia, seleção e recrutamento, capital, tecnologias, etc.

Análise da demanda: A etapa de compreensão da situação passa pela contextu- 
alização do problema proposto pela tarefa em análise, no cenário interno e externo à empresa. Nesta etapa, no nível externo à empresa, devem ser considerados os indicadores de saúde, aspectos sociais intervenientes, o momento técnico e tecnológico do contexto de inserção da empresa, bem como os condicionantes legais vigentes.

Análise da Tarefa: A análise da tarefa compreende a identificação e compreensão dois pontos: o trabalho prescrito (a instrução de trabalho) e os requisitos físicos para execução a tarefa. O primeiro ponto de observação inclui aspectos como o ambiente de inserção da tarefa (layout, mobiliário, equipamentos e espaços de trabalho); a carga de trabalho física e mental requerida; além dos aspectos psicos-sociológicos e de tempos de produção. O segundo ponto da análise envolve requisitos físicos da tarefa; abrange a natureza do trabalho muscular (estático e/ou dinâmico) e a postura requerida para execução da tarefa (que depende das características das superfícies de trabalho e assento, quando necessário); considerando ainda informações referentes a condições de acessibilidade aos sistemas de comunicação e acionamentos.

Análise da Atividade: A análise da atividade contempla a etapa de observação do trabalho efetivamente realizado, através da observação das atividades mentais e físicas do trabalhador. As atividades mentais reportam-se aos níveis de detecção, discriminação e interpretação das informações e, na sequência, os níveis de tomada de decisão e ação, respectivamente.

A AET permite que se elabore e formalize as seguintes etapas:

Diagnóstico Ergonômico: a etapa de diagnóstico ergonômico abrange o levantamento das condições técnicas de execução do trabalho; as condições ambientais em que a atividade ocorre; além das condições organizacionais do trabalho.

Caderno de Encargos e Recomendações: é o documento que reúne o conjunto de ações que devem ser realizadas para melhorar a atividade do trabalhador.

Após este processo, de recomendações e especificações ergonômicas produz-se um relatório final.

Com base nas etapas da Análise Ergonômica - AET procedeu-se o estudo de caso na empresa Ortonew.

\section{APRESENTAÇÃO DOS DADOS DO ESTUDO DE CASO}

Para a realização desta análise ergonômica do posto de trabalho, primeiramente contatou-se o proprietário da empresa-caso, Ortonew, com o objetivo de esclarecer os objetivos da pesquisa e obter sua permissão para a realização do referido estudo. A partir do consentimento do proprietário, foram agendadas duas visitas técnicas, sendo a primeira de caráter exploratório e superficial e a segunda investigativa e mais aprofundada. Após a realização da primeira visita técnica, onde foi realizada a observação de aspectos gerais da empresa, incluindo o posto de trabalho a ser analisado, se elaborou um questionário a ser aplicado na segunda visita técnica através de uma entrevista semiestruturada. Somados às respostas da entrevista, os registros fotográficos contribuíram para a identificação da real condição ergonômica do posto de trabalho estudado, possibilitando o apontamento de pontos positivos e negativos. Definida a demanda, deu-se início ao processo de observação da rotina de trabalho, ou seja, a descrição das atividades. 
Foram utilizadas três etapas da Análise Ergonômica - AET: Análise da Demanda; Análise da Tarefa e Análise da Atividade.

Na Síntese Ergonômica as duas etapas: Diagnóstico Ergonômico e Recomendações Ergonômicas. Neste ponto, é importante ressaltar que como a realização completa da etapa de Recomendações Ergonômicas exigiria um espaço de tempo maior do que o disponível, ficou restrita à indicação de direcionamentos ergonômicos superficiais. Contudo, estes apontamentos serão embasados nos resultados obtidos na etapa de Diagnóstico Ergonômico. O desenvolvimento de recomendações ergonômicas poderá ser objeto de estudo de pesquisas futuras.

\subsection{Análise da Demanda}

A demanda foi formulada na primeira visita técnica à Ortonew, oportunidade em que também se iniciaram as observações do posto de trabalho selecionado para análise - os processos de acabamento de órteses. Na segunda visita técnica, após sanar as dúvidas surgidas após o primeiro contato, através de uma entrevista com o técnico, pôde-se formular a seguinte demanda inicial: vários pontos e aspectos do posto de trabalho precisam ser melhorados, sobretudo os relativos à ergonomia física, tais como: mobiliário, posturas durante o trabalho; ausência do uso de EPIs; operação de instrumentos perigosos e os movimentos realizados. Em determinados momentos da entrevista, o técnico entrevistado mencionou a ocorrência de dores e desconfortos decorrente da realização dos processos de acabamento, especialmente aqueles que demandam movimentos repetitivos do trabalhador. Corroborando seu relato, o técnico apresentou aos pesquisadores um exame de ultrassonografia, realizado alguns dias antes da visita técnica, que retratou uma séria lesão em seu braço direito, alegadamente causada pelos anos de trabalho com movimentos repetitivos (FIGURA 2).

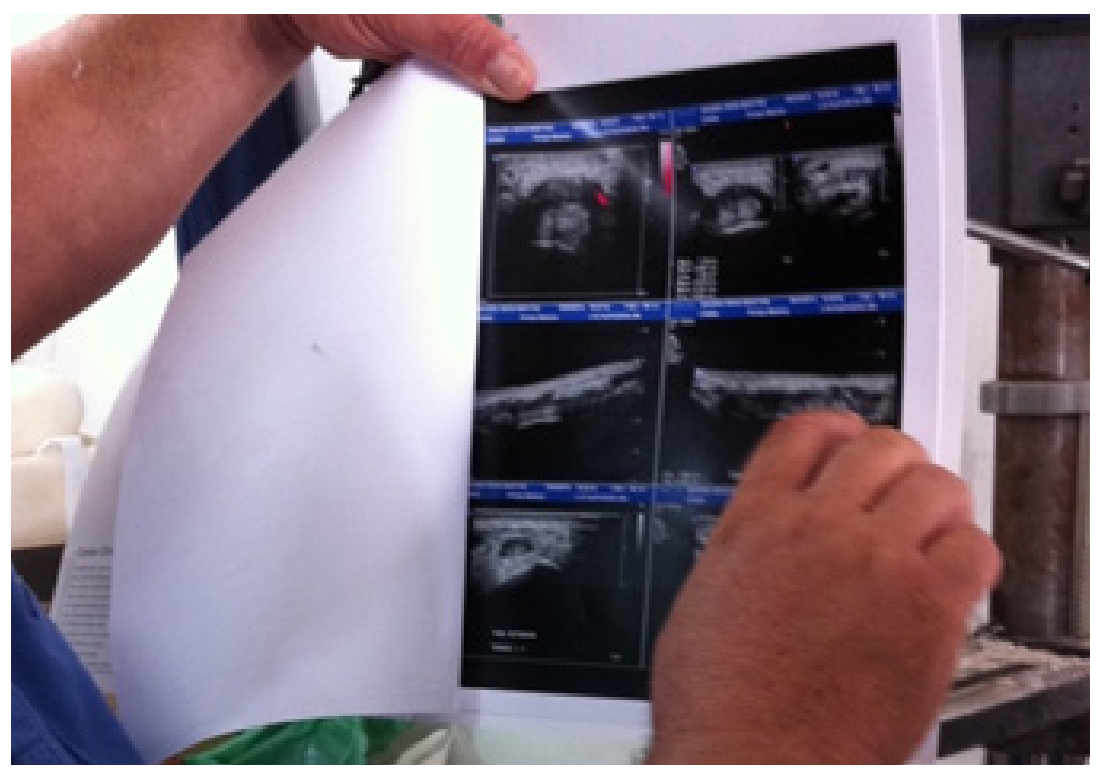

Figura 2: Exame de ultrassonografia exposto pelo técnico. Fonte: Autores, 2014. 


\subsection{Análise da Tarefa}

No posto de trabalho analisado, de processos de acabamento em órteses, o objetivo principal da tarefa é a finalização da produção de órteses personalizadas, visando o refinamento do produto, para que este seja simultaneamente funcional e confortável. Ora, se for apenas funcional, a órtese, além de não atingir os objetivos pelos quais foi prescrita, é capaz de desencadear novos problemas físicos no usuário, como o aparecimento de escaras, bolhas e quadros de dor. Por outro lado, se a órtese for confortável, mas pouco funcional, ao invés de melhorar e facilitar a condição de vida de seu usuário é capaz de piorar o seu quadro clínico. Para que se possa contemplar ambos os valores envolvidos - funcionalidade e conforto, a confecção de cada órtese é orientada por uma prescrição médica individual, onde são descritos detalhes relativos à sua conformação, mirando a correção do problema ortopédico diagnosticado. É importante ressaltar que os equipamentos e instalações da oficina precisam estar de acordo com as normas legais que regulamentam a atividade.

O procedimento inicial é a tomada de medidas do paciente com vistas à conformação de um molde de gesso negativo que possibilitará a moldagem de um modelo volumétrico idêntico ao membro, ou outra parte do corpo, a ser apoiado pela órtese (mão, perna, tronco, etc.). Depois de removido do paciente, o molde negativo é lubrificado com vaselina e preenchido com gesso para a produção de um molde positivo, a partir do qual então será moldada a forma bruta da órtese.

Deste momento em diante, com a obtenção da forma bruta da órtese, iniciam- se os processos de acabamento, é dizer, a partir daí começam efetivamente as ações do posto de trabalho objeto de estudo desta pesquisa.

Dependendo do membro ou parte do corpo a ser reabilitada pela órtese, poderá haver pequenas variações nos procedimentos de acabamento, pois cada diagnóstico exige um detalhamento particular. Por esta razão, neste estudo descreveremos o processo de acabamento de uma órtese infantil para pés.

A primeira ação da etapa de acabamento é a remoção dos excessos de material (polipropileno) da órtese bruta, utilizando-se para isso uma serra-fita. Em seguida, o técnico realiza, com o auxílio de uma furadeira de bancada, as furações necessárias para a incorporação de tiras de velcro e fivelas (FIGURA 3), que servirão para fixação e ajuste da órtese ao corpo de seu usuário. 


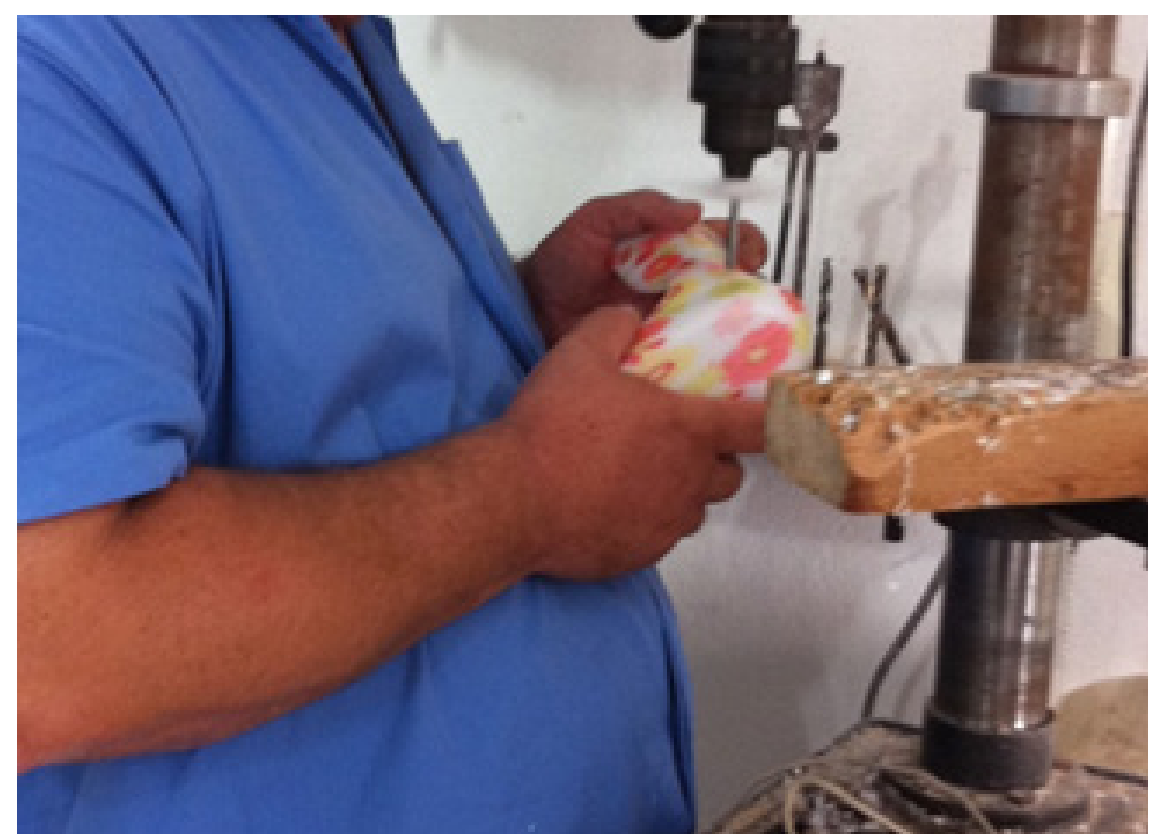

Figura 3: Furação para adição de tiras e fivelas de ajuste. Fonte: Autores, 2014.

As tiras de velcro e fivelas são fixadas com rebites metálicos, os quais são adicionados à órtese com o auxílio de uma bigorna e um martelo (FIGURA 4). A bigorna serve de apoio para a órtese enquanto fixam-se os rebites através de marteladas.

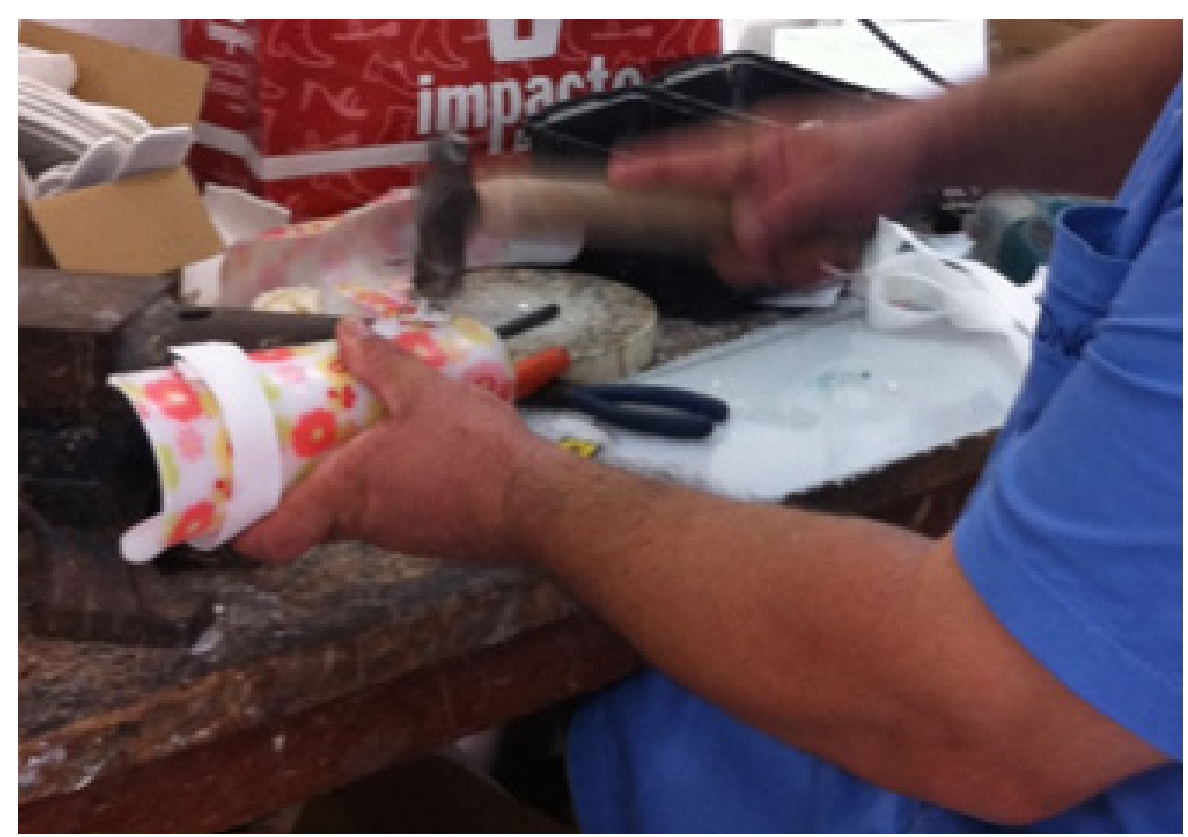

Figura 4: Fixação dos rebites metálicos. Fonte: Autores, 2014.

O processo seguinte é a adição de uma camada interna de E.V.A. (Etil Vinil Acetato), com o objetivo de oferecer uma interface macia e confortável entre o usuário e a órtese. Esta camada é colada à órtese com cola de contato (Figura 5), e é necessário aguardar cerca de cinco minutos após a sua aplicação até que a cola seque completamente e possa-se dar continuidade aos processos de acabamento. Com o intuito de 
certificar-se de que a camada de E.V.A. está bem colada e sem bolha de ar, o técnico utiliza suas próprias mãos para pressionar a camada contra a órtese. A camada de E.V.A. adicionada é sempre bem maior do que os limites da órtese e, após a secagem completa da cola, seu excesso é removido com uma lâmina cortante.

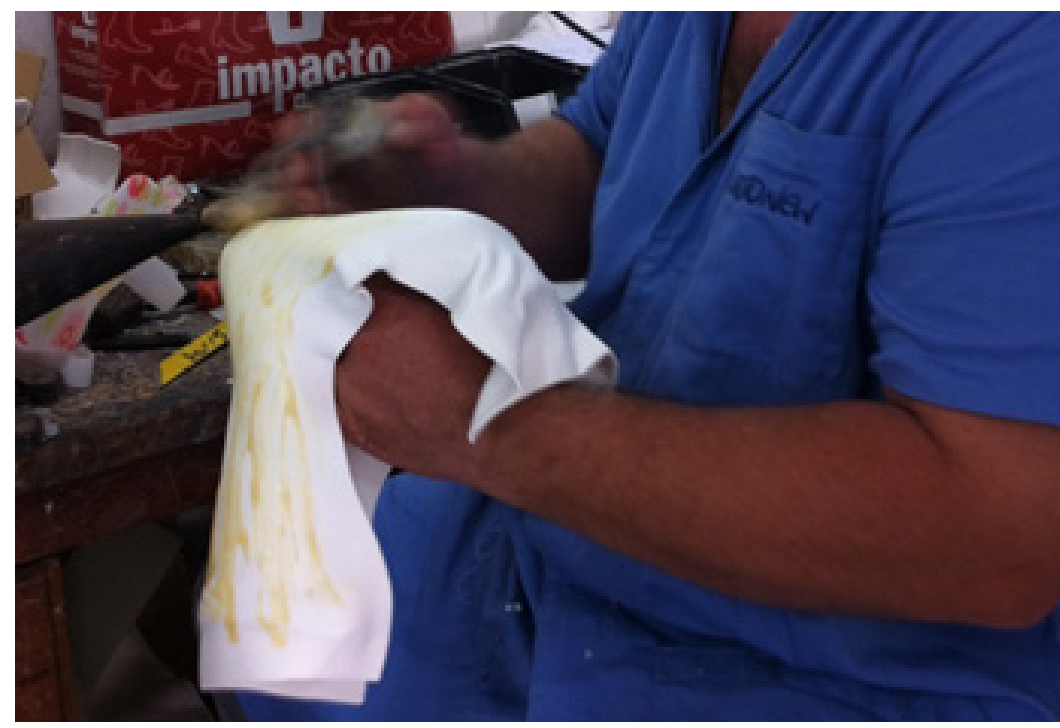

Figura 5: Aplicação da cola.

Fonte: Autores, 2014.

Neste momento, a órtese já está bem próxima de estar pronta, faltando apenas a conclusão da remoção de pequenas rebarbas, tanto no polipropileno quanto no E.V.A., deixando suas bordas completamente lisas para que não causem arranhões ou cortes no usuário. Nestes processos é utilizada a lixadeira e a esmerilhadora, além de uma lâmina afiada e cortante. Concluída esta etapa, a órtese está pronta, bastando apenas a finalização do serviço pelo técnico com a higienização da peça, utilizando um pedaço de estopa e solvente. O último passo da produção é anexar a ficha de pedido e a requisição médica à órtese para que a mesma possa ser entregue a seu usuário.

\subsection{Análise da Atividade}

A partir da realização da entrevista verificou-se que o trabalhador responsável pela produção das órteses possuía formação técnica específica para a função, estando devidamente capacitado. Com vinte e seis anos de experiência, sendo vinte deles trabalhando na Ortonew, o técnico formou-se no curso técnico em fabricação de órteses da AACD (Associação de Assistência à Criança Deficiente), em São Paulo. Segundo o entrevistado, este é o único local do Brasil a oferecer este tipo de curso técnico.

A análise da atividade considerou as ações realizadas pelo técnico durante os processos de acabamento de uma órtese, na oficina da empresa Ortonew. Observou-se que o posto de trabalho é composto por uma bancada principal, na qual fica depositado o material a ser usado e as ferramentas de trabalho (Figura 6).

Durante o processo, parte do trabalho é realizada na posição sentada em uma 
banqueta. Nesta posição, a parte lombar da coluna não está apoiada, o que acarreta um maior esforço na musculatura das costas, especialmente na musculatura lombar.

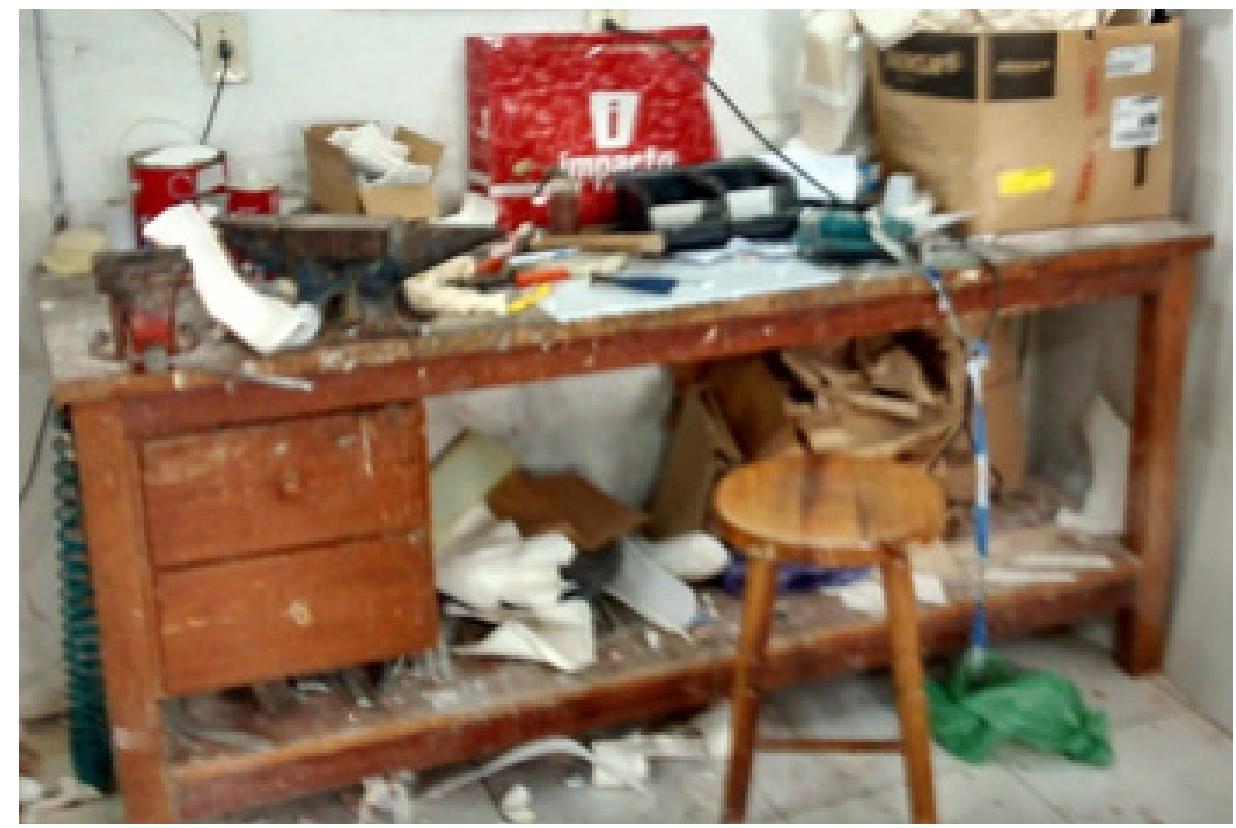

Figura 6: Bancada de trabalho do técnico em fabricação de órteses. Fonte: Autores, 2014.

Observou-se que para o uso de determinadas máquinas, tais como furadeira, esmerilhadora e lixadeira, o técnico necessita manter-se em pé (ver FIGURA 3). Essa variação de posições durante a realização do trabalho pode ser considerada um ponto positivo, pois a alternância contribui com a minimização de lesões advindas da permanência em uma mesma posição por longo período.

Especificamente na realização da primeira ação, de remoção dos excessos de polipropileno com a serra-fita, se identificou uma postura inadequada (inclinação lombar). No entanto, visto que o operador se mantém nesta posição por um curto espaço de tempo, o risco de surgirem lesões ocasionadas por esta posição/operação não é grave, o que, de toda forma, não dispensa a criação de uma alternativa ergonômica para corrigir tal postura.

Por outro lado, se pôde observar que o técnico não utiliza nenhum tipo de EPI (Equipamento de Proteção Individual) durante todo processo de fabricação das órteses. Como as operações são realizadas com máquinas e objetos cortantes, que oferecem perigos a seu operador, é recomendável a utilização de EPIs, especialmente óculos, luvas e máscara.

Nos processos de furação, fixação de tiras de velcro e colagem do E.V.A. ficam ainda mais evidentes a necessidade do uso de EPIs. Na operação da furadeira de bancada, o uso de óculos protegeria os olhos caso de alguma lasca de material se desprenda e seja projetada na direção do rosto do operador. Já na colagem, em função da toxicidade da cola de contato, seria importante a utilização de máscara, evitando a inalação de gases prejudiciais à saúde. Nos processos finais, de remoção de rebarbas de polipropileno e E.V.A., se observou uma situação bastante crítica, pois o instrumento utilizado é um caco de vidro (FIGURA 7), o que, segundo o técnico entrevis- 
tado, é comum e amplamente utilizado na fabricação de órteses. Ele ainda ressalta o fato de que realmente não existe ferramenta ou lâmina que realize a tarefa com a mesma qualidade que o caco de vidro oferece. No entanto, quando questionado sobre acidentes relativos ao uso deste instrumento adaptado, o técnico relatou que é bastante comum a incidência de cortes nas mãos, pois são realizados movimentos rápidos, repetitivos e sem o uso de luvas de proteção.

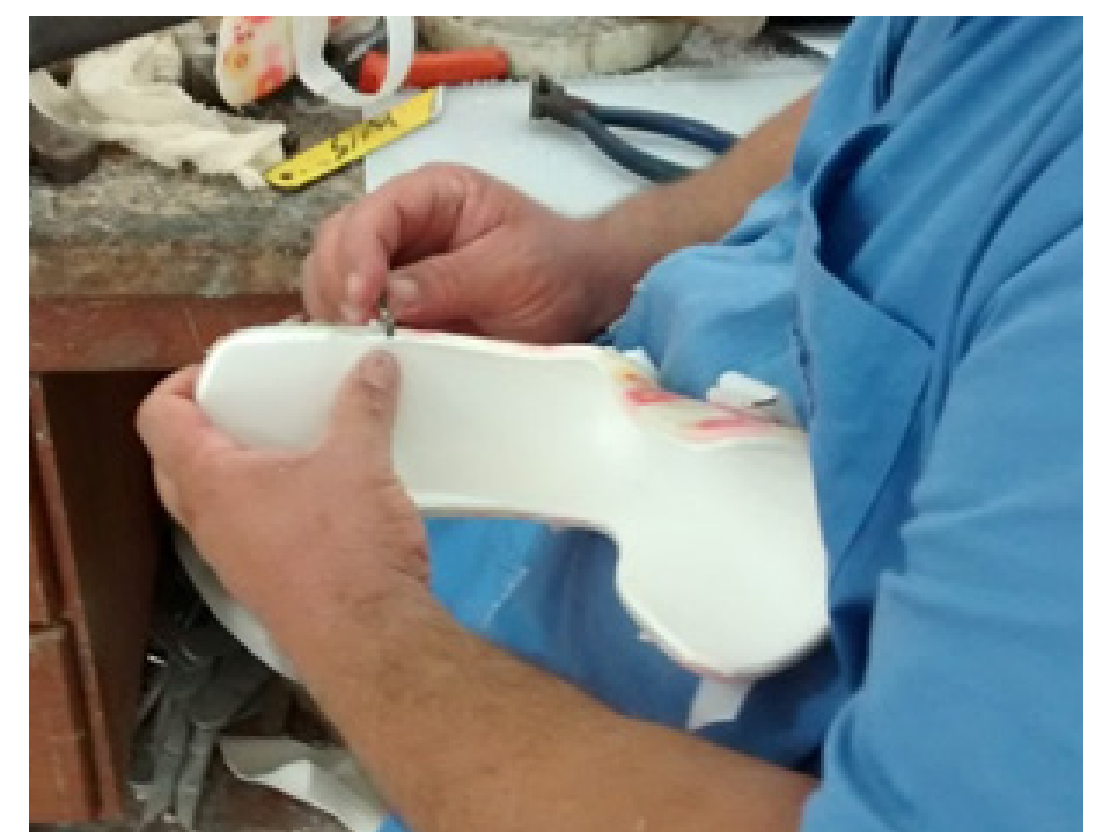

Figura 7: Remoção de rebarbas com o auxílio de um caco de vidro. Fonte: Autores, 2014.

Além dos aspectos relativos às ações/operações, a análise da atividade demonstrou também que o posto de trabalho está mal dimensionado, comprometendo a postura do técnico. A banqueta apresenta-se inadequada, pois não tem suporte para as costas ou para os braços e não é ajustável, portanto não atende o dimensionamento de uma cadeira ergonômica, colocando o trabalhador em uma posição desconfortável. Observa-se ainda a flexão do tronco como rotação e inclinação lateral do mesmo. O técnico para cumprir suas tarefas, adota diversas posturas, como a parte superior das costas curvada ou corcunda, cabeça direcionada para frente e região lombar curvada. A má postura sentada pode causar lesões e dores crônicas nas costas.

Analisando as atividades realizadas pelo técnico na confecção de uma órtese, constatou-se que os mobiliários e a posturas do técnico durante a realização das tarefas estão em desarmonia com as prescrições ergonômicas do trabalho. 


\begin{tabular}{|c|c|}
\hline \multicolumn{2}{|c|}{ Diagnóstico } \\
\hline $\begin{array}{c}\text { Pontos Positivos } \\
\end{array}$ & \begin{tabular}{|c|} 
Pontos Negativos \\
\end{tabular} \\
\hline $\begin{array}{l}\text { Alternancia entre trabalhar sentado e trabalhar } \\
\text { em pé; }\end{array}$ & $\begin{array}{l}\text { O trabalhador executa parte do trabalho sentado } \\
\text { em uma banqueta. Não tem apoio para a lombar } \\
\text { da coluna. Não é ajustável. }\end{array}$ \\
\hline $\begin{array}{l}\text { Permissão de pausas e intervalos no horário de } \\
\text { trabalhos; }\end{array}$ & $\begin{array}{l}\text { Posturas inadequadas: parte superior das costas } \\
\text { curvada ou corcunda, cabeça direcionada para } \\
\text { frente e região lombar curvada que podem incidir } \\
\text { em lesões e dores crônicas nas costas. }\end{array}$ \\
\hline Horários de trabalho relativamente flexível; & $\begin{array}{l}\text { Não utiliza Equipamento de Proteção Individual, } \\
\text { (máscaras, óculos, luvas) já que trabalha com } \\
\text { máquinas e objetos cortantes. }\end{array}$ \\
\hline Música ambiente; & $\begin{array}{l}\text { Postura inadequada (inclinação lombar), no uso } \\
\text { da serra-fita. }\end{array}$ \\
\hline \multirow[t]{3}{*}{ Clima organizacinoal amistoso. } & $\begin{array}{l}\text { Uso de instrumentos de trabalho inadequado, } \\
\text { como o caco de vidro. }\end{array}$ \\
\hline & Movimentos repetitivos. \\
\hline & $\begin{array}{l}\text { Posto de trabalho e mobiliários mal dimensionado. } \\
\text { Ambiente com temperaturas elevadas no verão. }\end{array}$ \\
\hline
\end{tabular}

Tabela 1: Diagnóstico da análise ergonômica do posto de trabalho.

Fonte: Autores, 2014.

\section{RESULTADOS: DIAGNÓSTICO ERGONÔMICO}

Após o entendimento das tarefas (trabalho prescrito) e das atividades (trabalho real) foi possível a identificação de pontos positivos e negativos relacionados à ergonomia física de uma oficina de fabricação de próteses e órteses, mais especificamente associados ao posto de trabalho dos processos de acabamento de órteses. Portanto, a seguir serão levantados alguns aspectos que podem ser incentivados e outros que precisam de ajustes ou adequações.

Apesar da identificação de inúmeros pontos ergonomicamente negativos, também foram observados alguns aspectos positivos no posto de trabalho estudado, tais como: alternância entre trabalho sentado e trabalho em pé; permissão de pausas/intervalos; horário de trabalho relativamente flexível; música ambiente e clima organizacional amistoso. A alternância de posições durante o trabalho, assim como as pausas ou intervalos, minimizam as ocorrências de lesões advindas de longos períodos em uma mesma posição. Os outros aspectos positivos apontados também devem ser mantidos e incentivados, contudo fazem parte da ergonomia organizacional, e este estudo foca-se na ergonomia física.

Os principais pontos negativos identificados são relacionados ao mobiliário (bancada e cadeira), às posturas, à ausência de uso de EPIs e uso de instrumentos perigosos.

O posto de trabalho deve passar por uma reorganização significativa, principalmente a sua bancada e cadeira.

Na bancada, onde ocorre a maioria das ações, os instrumentos não são facilmente identificados, o que dificulta o alcance e a manipulação dos mesmos. A banca- 
da utilizada não é dimensionada conforme critérios ergonômicos não têm encosto, ajuste e nem espaço suficiente para a acomodação das pernas, como no caso de uma cadeira ergonômica.

Para solucionar a deficiência apontada, há no mercado vários modelos de cadeiras ergonomicamente apropriadas para o trabalho na posição sentada, enfocando, entre outros, aos aspectos anatômicos e antropométricos. As posturas adotadas nas ações do posto de trabalho analisado merecem atenção, pois se observou fatores de risco para o desenvolvimento de LER (Lesão por Esforço Repetitivo) e/ou DORT (Disfunções Ortopédicas Relativas ao Trabalho).

Os resultados da entrevista e das observações também evidenciam a necessidade e importância do uso dos EPIs durante a execução dos processos de acabamento das órteses. Segundo o técnico entrevistado, o empregador disponibiliza EPIs aos trabalhadores, porém não há cobrança ou conscientização quanto ao seu uso, então os funcionários acabam não os utilizando por considerarem que os EPIs dificultam e atrasam o trabalho. Em todas as figuras utilizadas neste estudo pode-se perceber a ausência de EPIs. O único EPI utilizado e percebido foi o jaleco, mas sua funcionalidade é duvidosa, pois não se tem certeza se é de fato um EPI ou apenas um uniforme.

Outro aspecto que precisa ser resolvido é a adaptação de instrumentos, tal como o uso de cacos de vidro como aparador de rebarbas. Além deste, há outros instrumentos improvisados e que foram desenvolvidos empiricamente pelos técnicos. Em termos funcionais estes instrumentos apresentam boas soluções, afinal contribuem eficientemente aos seus propósitos. No entanto, em termos de segurança e saúde dos trabalhadores, os instrumentos improvisados possuem sérios problemas ergonômicos, pois, como relatado pelo próprio entrevistado, ocasionam constantes lesões e cortes em suas mãos.

Além dos aspectos descritos acima, o técnico também mencionou inadequações e desconfortos sobre as características ambientais da oficina, tal como as altas temperaturas em dias de calor intenso, especialmente no verão. A oficina é equipada com dois ventiladores, mas, segundo o entrevistado, eles não são suficientes para o alívio da sensação de calor desconfortável, devendo ser considerada a hipótese de climatização do local como forma de contribuir para uma melhor ergonomia do posto de trabalho.

\section{CONCLUSÕES}

A qualidade do ambiente de trabalho é um fator que afeta diretamente o trabaIhador, e este é um elemento fundamental durante o processo de produção. Com a realização de uma AET (Análise Ergonômica do Trabalho) num posto de trabalho de uma oficina de próteses e órteses, foi possível verificar pontos positivos e negativos relativos às suas características ergonômicas.

Como ficou evidenciado na confrontação da descrição da tarefa com a descrição da atividade, o posto de trabalho necessita de reorganização, correções e ajustes. Possiveis modificações englobariam aspectos de lay-out, mobiliário, posturas e equipamentos. Estas demandas sugerem possibilidades interessantes para trabalhos posteriores ou pesquisas futuras, com foco no desenvolvimento e implantação de 
melhorias no posto de trabalho estudado.

O diagnóstico formulado demonstra inúmeras possibilidades de intervenções ergonômicas. Possivelmente, a extensa lista de defasagens ergonômicas advém do caráter quase artesanal das oficinas de próteses e órteses. Esta hipótese poderia ser testada e/ou confirmada em um trabalho futuro, através de um comparativo após a visitação e avaliação de outras empresas do mesmo ramo, procurando entender quais aspectos se repetem no segmento e quais são reflexos da gestão interna e particular de cada empresa.

Além dos fatores relativos à ergonomia física, também seria relevante o desenvolvimento de outros estudos que verifiquem a realidade de uma oficina de próteses e órteses quanto à ergonomia cognitiva e também em relação à ergonomia organizacional.

Portanto, o diagnóstico aqui descrito, sobre as atividades em uma oficina de órteses, pode contribuir para a formulação de recomendações ergonômicas que possibilitarão melhorias na qualidade de vida dos funcionários, bem como em seus produtos. 


\section{REFERÊNCIAS}

BERSCH, Rita. Introdução a Tecnologia Assistida. Centro Especializado em Desenvolvimento Infantil. Porto Alegre, 2008. Disponível em <http://www.assistiva. com.br/Introducao_Tecnologia_Assistiva.pdf>. Acesso em 05 de Abril de 2014.

BRASIL. Comitê de Ajudas Técnicas. Secretaria Especial dos Direitos Humanos. Ata VII Reunião do Comitê de Ajudas Técnicas. 2007. Disponível em: <http://www. infoesp.net/CAT_Reuniao_VII.pdf>. Acesso em: 04 de Abril de 2014.

BRASIL. Decreto 7.612, de 17 de novembro de 2011. Institui o Plano Nacional dos Direitos da Pessoa com Deficiência - Plano Viver sem Limite. 2011. Disponível em <http://www.planalto.gov.br/ccivil_03/_Ato2011-2014/2011/Decreto/D7612.htm>. Acesso em 15 de Março de 2014.

BRASIL. Presidência da República. Casa Civil. Convenção sobre os direitos das pessoas com deficiência. 2009. Disponível em <http://www.planalto.gov.br/ccivil_03/_Ato2007-2010/2009/Decreto/D6949.htm>. Acesso em 04 de Abril de 2014.

OLIVEIRA, Luiza Maria Borges. Secretaria de Direitos Humanos da Presidência da República. Cartilha do Censo 2010: Pessoas com Deficiência. Brasília: SDH-PR/ SNPD, 2012. Disponível em <http://www.pessoacomdeficiencia.gov.br/app/sites/ default/files/publicacoes/cartilha-censo-2010-pessoas-com-deficienciareduzido. pdf>. Acesso em 09 de Abril de 2014.

DUL, Jan; WEERDMEESTER, Bernard. Ergonomia Prática. Tradução de Itiro lida. 2.

ed. São Paulo: Edgard Blücher, 2004.

IIDA, Itiro. Ergonomia: projeto e produção. 6. ed. São Paulo: Edgar Blücher, 2005.

INSTITUTO BRASILEIRO DE GEOGRAFIA E ESTATÍSTICA (IBGE). Censo 2010. 2010. Disponível em <ftp://ftp.ibge.gov.br/Censos/Censo_Demografico_2010/Caracteristicas_Gerais_Religiao_Deficiencia/tab1_3.pdf>. Acesso em 27 de Março de 2014.

SALVENDY, Gavriel. Handbook of Human Factors and Ergonomics. Hoboken, NJ: John Wiley \& Sons, 2006.

SARTORETO, Maria Lúcia; BERSCH, Rita. Assistiva: Tecnologia e Educação. Disponível em <http://www.assistiva.com.br/tassistiva.html>. Acesso em 09 de Abril de 2014.

SHUVAL, Kerem; DONCHIN, Milka. Prevalence of upper extremity musculoske- 
letal symptoms and ergonomic risk factors at a Hi-Tech company in Israel. International Journal of Industrial Ergonomics, v. 35, p. 569-581, 2005. Disponivel em <http://www.sciencedirect.com/science/article/pii/S0169814105000156>. Acesso em 28 de Março de 2014.

VIDAL, Mário César. Introdução à Ergonomia. Rio de Janeiro: COPPE/UFRJ, s.d. Disponivel em <http://www.ergonomia.ufpr.br/Introducao\%20a\%20Ergonomia\%20 Vidal\%20CESERG.pdf>. Acesso em 02 de Abril de 2014.

WISNER, Alain. A inteligência do trabalho: textos selecionados de ergonomia. São Paulo: Fundacentro, 1994. 